\title{
Enhancement of stress tolerance in transgenic tobacco plants constitutively expressing AtIpk2 $\beta$, an inositol polyphosphate 6-/3-kinase from Arabidopsis thaliana
}

\author{
Lei Yang $\cdot$ Renjie Tang $\cdot$ Jinqi Zhu $\cdot$ Hua Liu $\cdot$ Bernd Mueller-Roeber $\cdot$ \\ Huijun Xia · Hongxia Zhang
}

Received: 11 May 2007/ Accepted: 14 November 2007/Published online: 30 December 2007

(C) The Author(s) 2007

\begin{abstract}
Inositol phosphates (IPs) and their turnover products have been implicated to play important roles in stress signaling in eukaryotic cells. In higher plants genes encoding inositol polyphosphate kinases have been identified previously, but their physiological functions have not been fully resolved. Here we expressed Arabidopsis inositol polyphosphate 6-/3-kinase (AtIpk2 $\beta$ ) in two heterologous systems, i.e. the yeast Saccharomyces cerevisiae and in tobacco (Nicotiana tabacum), and tested the effect on abiotic stress tolerance. Expression of AtIpk $2 \beta$ rescued the salt-, osmotic- and temperature-sensitive growth defects of a yeast mutant strain $(\arg 82 \Delta)$ that lacks inositol polyphosphate multikinase activity encoded by the ARG82/IPK2 gene. Transgenic tobacco plants constitutively expressing AtIpk $2 \beta$ under the control of the Cauliflower Mosaic Virus 35S promoter were generated and found to exhibit improved tolerance to diverse abiotic stresses when compared to wild type plants. Expression patterns of various stress responsive
\end{abstract}

Electronic supplementary material The online version of this article (doi:10.1007/s11103-007-9267-3) contains supplementary material, which is available to authorized users.

L. Yang $\cdot$ R. Tang $\cdot$ J. Zhu $\cdot$ H. Liu $\cdot$ H. Zhang $(\bowtie)$

National Key Laboratory of Plant Molecular Genetics,

Institute of Plant Physiology and Ecology, Shanghai

Institutes for Biological Sciences, Chinese Academy

of Sciences, 300 Fenglin Road, Shanghai 200032, China

e-mail: hxzhang@sippe.ac.cn

H. Xia

Key Laboratory of MOE for Plant Developmental Biology,

College of Life Sciences, Wuhan University, Wuhan 430072,

China

B. Mueller-Roeber

University of Potsdam, Karl-Liebknecht-Str. 24-25, Haus 20,

14476 Potsdam-Golm, Germany genes were enhanced, and the activities of anti-oxidative enzymes were elevated in transgenic plants, suggesting a possible involvement of AtIpk $2 \beta$ in plant stress responses.

Keywords Arabidopsis thaliana $\cdot$ AtIpk $2 \beta \cdot$ Inositol phosphate $\cdot \mathrm{IP}_{3} \cdot$ Stress tolerance $\cdot$ Transgenic tobacco

\section{Introduction}

During their life plants are often challenged with various types of abiotic stresses. Proper physiological and biochemical responses to such stresses are controlled by an array of stress-dependent signal transduction pathways (Xiong et al. 2002). Several signaling molecules and second messengers including calcium ions $\left(\mathrm{Ca}^{2+} ;\right.$ Knight et al. 1996; Knight et al. 1997) and inositol 1,4,5-trisphosphate $\left(\mathrm{IP}_{3}\right.$; Takahashi et al. 2001) have been demonstrated to be important elements of signaling pathways that link the perception of stress to various types of downstream responses. As one of the central molecules in cell signaling, $\mathrm{IP}_{3}$ is subject to phosphorylation and dephosphorylation by specific inositol phosphate kinases and phosphatases, respectively, which helps to control intracellular $\mathrm{IP}_{3}$ concentration (Pattni and Banting 2004).

In higher plants, over-expression of an inositol polyphosphate 5-phosphatase (Ins5Pase), possibly leading to intracellular degradation of $\mathrm{IP}_{3}$, modulated stress and $\mathrm{ABA}$ signal transduction (Perera et al. 2002; Burnette et al. 2003). Likewise, mutation of an inositol polyphosphate 5-phosphatase gene (CVP2) results in increased sensitivity to $\mathrm{ABA}$ and vein patterning defects in cotyledons (Carland and Nelson 2004). $\mathrm{IP}_{3}$ can also be hydrolyzed by FRY1-like inositol polyphosphate 1-phosphatases (Ins1Pases; Xiong et al. 2002). The fryl mutant of Arabidopsis accumulated 
around ten-fold more $\mathrm{IP}_{3}$ than the corresponding wild type, exhibited hypersensitivity towards ABA, and was compromised in tolerance to freezing, drought and salt stresses (Xiong et al. 2001). These data demonstrate the importance of inositol polyphosphate phosphatases in $\mathrm{IP}_{3}$ metabolism and $\mathrm{IP}_{3}$-mediated stress signal transduction. However, evidence for a role of inositol polyphosphate kinases in relation to stress tolerance is currently lacking in plants.

Inositol 1,4,5-trisphosphate 3-kinase (IP3K) and more generally inositol polyphosphate kinases play an essential role in cellular signal transduction and maintenance of $\mathrm{Ca}^{2+}$ homeostasis by phosphorylating inositol 1,4,5-trisphosphate $\left(\mathrm{IP}_{3}\right)$ to inositol 1,3,4,5-tetrakisphosphate $\left(\mathrm{IP}_{4}\right.$; Communi et al. 1995). Both $\mathrm{IP}_{3}$ and $\mathrm{IP}_{4}$ are second messengers responsible for $\mathrm{Ca}^{2+}$ mobilization from intracellular stores (Berridge 1997). $\mathrm{IP}_{4}$ itself is also able to regulate cytosolic $\mathrm{Ca}^{2+}$ concentration by promoting $\mathrm{Ca}^{2+}$ sequestration (Hill et al. 1988). In Arabidopsis thaliana, IP3K is encoded by two distinct genes, AtIpk $2 \alpha$ and AtIpk $2 \beta$, which are ubiquitously expressed in mature tissues (Stevenson-Paulik et al. 2002; Xia et al. 2003). Both of the Arabidopsis IP3Ks use $\mathrm{IP}_{3}$ as a substrate and display dual-specificity inositol polyphosphate 6-/3-kinase activities that successively phosphorylate $\mathrm{IP}_{3}$ to generate inositol 1,3,4,5,6-pentakisphosphate $\left(\mathrm{IP}_{5}\right)$ predominantly via an inositol 1,4,5,6-tetrakisphosphate $\left(\mathrm{IP}_{4}\right)$ intermediate (Stevenson-Paulik et al. 2002; Xia et al. 2003). Recently it was reported that AtIpk $2 \alpha$ plays a role in pollen germination and root growth (Xu et al. 2005), while AtIpk2 $\beta$ functions in axillary shoot branching through the auxin signaling pathway (Zhang et al. 2007) and phytate synthesis (Stevenson-Paulik et al. 2005).

Although AtIpk $2 \beta$ has well been characterized at the biochemical level and has been shown to participate in plant development, it remained unclear whether it is also involved in stress signaling. In this study we demonstrate that AtIpk $2 \beta$ restores the salt-, osmotic- and temperaturesensitive growth defects of a yeast mutant strain ( $\arg 82 \Delta)$ deficient for the ARG82/IPK2 gene that encodes inositol polyphosphate multikinase. We also show that constitutive expression of AtIpk $2 \beta$ in transgenic tobacco enhances its tolerance towards various abiotic stresses. Thus, inositol polyphosphate kinase encoded by AtIpk $2 \beta$ very probably plays an important role in signaling pathways controlling the cellular response to abiotic stresses.

\section{Materials and methods}

Expression of AtIpk2 $\beta$ in yeast mutant $\arg 82 \Delta$

The $S$. cerevisiae arg82/Ipk2 deletion strain (derived from BY4741; Mat a; his $3 \Delta 1$; leu2 $\Delta 0 ; \operatorname{met} 15 \Delta 0 ; \operatorname{ura} 3 \Delta 0$;
YDR173c::kanMX4) was obtained from EUROSCARF (http://www.web.uni-frankfurt.de/fb15/mikro/euroscarf/). In this strain, the ARG82/IPK2 allele is disrupted through insertion of the kanamycin resistance gene, kanMX4. The AtIpk $2 \beta$ open reading frame was cloned into yeast expression plasmid pYX212. The resulting plasmid, pYX212AtIpk2 $\beta$, was used to transform the yeast mutant. The wild type strain BY4741 was used as control. Ten-fold serial dilutions (starting at $\mathrm{OD}_{600}=1.0$ ) of each strain were plated on YPD medium (1\% yeast extract, $2 \%$ peptone, $2 \%$ glucose) supplemented with either $\mathrm{NaCl}(0.4$ or $0.8 \mathrm{M})$ or mannitol $(0.4$ or $0.8 \mathrm{M})$, and incubated at $30^{\circ} \mathrm{C}$ for $48 \mathrm{~h}$. For growth at $37^{\circ} \mathrm{C}$, yeast cells were grown on media containing no extra $\mathrm{NaCl}$ or mannitol. Each experiment was repeated at least three times. For growth in liquid YPD medium, cells were cultured at $30^{\circ} \mathrm{C}$ for three days to saturation $\left(\mathrm{OD}_{600}=12.0\right)$. Five $\mu \mathrm{l}$ of the cell culture were used to inoculate $3 \mathrm{ml}$ of synthetic defined minimal medium supplemented with different concentrations of $\mathrm{NaCl}$ or mannitol. Cell density was measured at $A_{600}$.

Quantitative real-time PCR analysis of AtIpk2 $\beta$ expression in Arabidopsis

Ten-day-old Arabidopsis seedlings grown on MS medium were used for different treatments as described previously (Shi and Zhu 2002). RNA was extracted with TRIZOL Reagent (Invitrogen) and reverse transcription of RNA was carried out using M-MLV RTase Synthesis Kit (TaKaRa). Quantitative real-time PCR was performed using the Rotor-Gene 3000 Series real time DNA amplification system under the following conditions: $95^{\circ} \mathrm{C}$ for $10 \mathrm{~s} ; 40$ cycles of $95^{\circ} \mathrm{C}$ for $5 \mathrm{~s}, 60^{\circ} \mathrm{C}$ for $20 \mathrm{~s}$. AtIpk $2 \beta$-specific primers were used (Table 1). Melting curve analysis was included to verify specificity of the DNA amplification. Expression of the reference gene Actin, which served as quantifying control, was monitored using gene-specific forward and reverse primers (Table 1). Data analysis was performed with Rotor-Gene software 6.0.

Vector construction and plant transformation

To create a Cauliflower Mosaic Virus (CaMV) 35S plant expression construct, the $903 \mathrm{bp}$ long AtIpk $2 \beta$ cDNA containing the complete open reading frame was inserted via XbaI-SalI sites into the binary vector pBinAR-HPT. The resulting construct was introduced into Agrobacterium tumefaciens (strain LBA4404). Tobacco (Nicotiana tabacum cv. SR-1) leaf disks were infected with the transformed Agrobacteria. After two days of co-cultivation, the 
Table 1 Gene-specific primers used in this study

\begin{tabular}{|c|c|}
\hline Primer name & Primer sequence \\
\hline \multicolumn{2}{|c|}{ For yeast expression vector } \\
\hline pYX-F & 5'-CTCCCATGGTAATGCTCAAAGTCCCTG-3 \\
\hline pYX-R & 5'-GATTGTCGACCTAGCGCCCGTTCTC-3' \\
\hline \multicolumn{2}{|c|}{ For real-time RT-PCR } \\
\hline AtIPK $2 \beta-\mathrm{F}$ & 5'-CCACGGTTTCGTTGGGGTTC-3' \\
\hline AtIPK $2 \beta-\mathrm{R}$ & 5'-GTTACAACCGCCATAAACCTCTG-3' \\
\hline AtActin2-F & 5'-CATCCTCCGTCTTGACCTTGC-3' \\
\hline AtActin2-R & 5'-CAAACGAGGGCTGGAACAAG-3' \\
\hline \multicolumn{2}{|l|}{ For RT-PCR } \\
\hline NtActin-F & 5'-TTACGCCCTTCCTCATGCAATT-3' \\
\hline NtActin-R & 5'-GGCGCCACCACCTTGATCTTC-3' \\
\hline AY562132-F & 5'-GTAGCATTGTTGGTGGTGGTGTG-3' \\
\hline AY562132-R & $5^{\prime}$ - ACCGTGGAGCAGTCAATGGAAG-3' \\
\hline AY554169-F & 5'- ACAGTCGTGAGCATTCCCAAC- $3^{\prime}$ \\
\hline AY554169-R & 5'-CCAAACCTTCTGTGCTACCTC-3' \\
\hline AY554170-F & $5^{\prime}$-CCGGAGTGAAGGGGATGG-3' \\
\hline AY554170-R & 5'-CAAGCAATGTGAATGGTATGTGAG-3' \\
\hline NtERD10B-F & 5'-CAATTTAGTGCAGGCCAGGC-3' \\
\hline NtERD10B-R & 5'-GGTCCATGGTGGCCAGGAAG-3' \\
\hline NtERD10C-F & $5^{\prime}$-GGGTAGCGCAAACGTGGAG-3' \\
\hline NtERD10C-R & 5'-CTTTTCCCTCAGCCTCGTGC-3' \\
\hline
\end{tabular}

explants were transferred to regeneration medium containing 1-mg/l BAP, 0.1-mg/l NAA, 50-mg/l hygromycin and 200-mg/l ampicillin. Regenerated shoots were separated from the calli and transferred onto rooting medium containing MS salts, 0.1-mg/l NAA and $50-\mathrm{mg} / \mathrm{l}$ hygromycin. Rooted shoots were transplanted into soil. Seeds were harvested and homozygous plants were screened on a 12-h light/12-h dark photoperiod.

\section{Salt stress tolerance tests}

Wild type and homozygous $T_{2}$ transgenic seeds were surface sterilized with a solution of $10 \%$ commercial bleach $(0.525 \%$ sodium hypochlorite) for $10 \mathrm{~min}$, and washed three times with sterile water. For germination assays, seeds were plated on MS medium supplemented with different concentrations of $\mathrm{NaCl}(0,100$ and $200 \mathrm{mM})$. For root growth measurements, 10-day-old seedlings cultured on solid MS medium were transferred to MS medium supplemented with different concentrations of $\mathrm{NaCl}$. Plates were oriented vertically with seedlings kept upside down. Three replicates were performed for each experiment. Root length was recorded after seven days of treatment. To monitor stress effects on the growth of wild type and AtIpk $2 \beta$ expressing plants, 15-day-old seedlings were transferred to MS medium supplemented with 0, 100, 200 or $300 \mathrm{mM} \mathrm{NaCl}$, and cultured at $25 \pm 2^{\circ} \mathrm{C}$ with cool white fluorescent light $\left(\sim 125 \mu \mathrm{mol} \mathrm{m}{ }^{-2} \mathrm{~s}^{-1}\right)$ under short day condition (12-h light/12-h dark). For salt stress treatments and ion measurements, wild type and transgenic seedlings were transferred to pots containing soil. Plants were watered bi-weekly with $1 / 8$ concentrated MS salt solution supplemented with or without $200-\mathrm{mM} \mathrm{NaCl}$ and grown at $25 \pm 2{ }^{\circ} \mathrm{C}$ with cool white fluorescent light $\left(\sim 125 \mu \mathrm{mol} \mathrm{m} \mathrm{m}^{-2} \mathrm{~s}^{-1}\right), 70 \%$ humidity, under long-day conditions (16-h light/8-h dark) for 6 weeks. Mature plants treated in the same way were also used to determine cellular $\mathrm{Na}^{+}$concentrations. The third leaf from the top of each plant was collected and dried at $90^{\circ} \mathrm{C}$ for $24 \mathrm{~h}$, and the dry weight of each sample was measured. The dried leaf material was immersed in 0.1-M HAc, followed by water bath incubation at $90^{\circ} \mathrm{C}$ for $2.5 \mathrm{~h}$, and analyzed for $\mathrm{Na}^{+}$ content using atomic absorption spectrophotometry. For hydroponic salt tolerance experiments, wild type plants and two independent transgenic lines $\left(T_{2}\right.$ generation) were grown hydroponically in Hoagland solution. Plants were grown at $25 \pm 2{ }^{\circ} \mathrm{C}$ with cool white fluorescent light $\left(\sim 125 \mu \mathrm{mol} \mathrm{m}^{-2} \mathrm{~s}^{-1}\right), 70 \%$ humidity, under long-day conditions (16-h light/8-h dark). The nutrient solution was replaced weekly.

\section{Oxidative stress experiments}

Malondialdehyde (MDA) concentration was determined as a biomarker for oxidative stress. To measure MDA concentration, leaf samples from plants grown at 200-mM $\mathrm{NaCl}$ were ground in $5 \mathrm{ml}$ of $0.1 \%$ trichlor acetic acid (TCA) and mixed with $5 \mathrm{ml}$ of $0.5 \%$ thiobarbituric acid. The samples were then boiled for $10 \mathrm{~min}$, cooled down to room temperature and centrifuged at $1,200 \times g$. The cleared supernatant was analyzed by monitoring the difference in absorbance at $A_{532}$ and $A_{600}$. For oxidative damage experiments, leaf disks of $1.5-\mathrm{cm}$ diameter were excised from healthy and fully expanded leaves of two-month-old tobacco plants. The disks were floated in a 10-ml solution with different concentrations of $\mathrm{H}_{2} \mathrm{O}_{2}$ or water (control) for $72 \mathrm{~h}$. Chlorophyll a and b concentrations were measured as described previously (Lichtenthaler 1987). The treatment was carried out with continuous white light at $25 \pm 2{ }^{\circ} \mathrm{C}$. The experiment was repeated at least three times.

Enzyme assays and protein determination

Enzyme assays were carried out spectrophotometrically using a nucleic acid and protein analyzer (Du 640, Beckman Coulter). One-month-old seedlings were treated with 
$\mathrm{H}_{2} \mathrm{O}$ or $1 \% \mathrm{H}_{2} \mathrm{O}_{2}$ for $12 \mathrm{~h}$, and ground in extraction buffer ( $1 \mathrm{mM}$ ascorbate in $50-\mathrm{mM}$ potassium phosphate buffer, $\mathrm{pH} 7.8$ ) at a ratio of $0.1 \mathrm{~g}$ leaf material $/ 1 \mathrm{ml}$ ice-cold extraction buffer. The slurry was transferred to a centrifuge tube and centrifuged at $20,000 \times g$ at $4^{\circ} \mathrm{C}$ for $20 \mathrm{~min}$. The supernatant was used for enzyme activity assays and total protein determination as described previously (Badawi 2004; Bradford 1976). Ascorbate peroxidase (APX) activity was determined by measuring the rate of ascorbate oxidation at $A_{290}$ in a $100-\mu$ l-reaction mixture (1-mM EDTA in $50-\mathrm{mM}$ potassium phosphate buffer, $\mathrm{pH} 7.8$, $0.2-\mathrm{mM}$ ascorbate, $20-\mathrm{mM} \mathrm{H}_{2} \mathrm{O}_{2}$ and 5 - $\mu$ l soluble protein extract). APX activity is expressed as micromoles of ascorbate oxidized per minute per milligram of protein. Catalase (CAT) activity was measured by monitoring the decrease in absorbance at $A_{240}$ caused by the disappearance of $\mathrm{H}_{2} \mathrm{O}_{2}$ in a 100- $\mu$-reaction mixture (1-mM EDTA in 50-mM potassium phosphate buffer, $\mathrm{pH} 7.8,20-\mathrm{mM} \mathrm{H}_{2} \mathrm{O}_{2}$ and 5- $\mu$ l protein extract). The activity of superoxide dismutase (SOD) was measured at $A_{560}$, in a $3-\mathrm{ml}$ reaction mixture (13.05-mM DL-methionine, $0.1-\mu \mathrm{M}$ EDTA, $0.075-\mathrm{mM}$ Nitro Blue tetrazolium chloride and $2-\mu \mathrm{M}$ riboflavin in 50-mM phosphate buffered saline, $\mathrm{pH} 7.8$, and $100-\mu$ protein extract).

Whole plant drought tolerance test

Wild type and transgenic plant seeds were surface sterilized as described above. Seedlings germinated on MS medium were transplanted to soil. After two months, healthy plants of the same size and age were pooled into two groups. For the first group (12 individual plants, each grown in a 6.5-inch pot), plants were irrigated with $60 \mathrm{~g} / 1$ PEG-6000 to simulate drought stress. After 21 days, the plants were photographed. Simultaneously, plants of the second group were subjected to drought stress by omitting watering. After three weeks, the plants were re-hydrated and observed for recovery. Photos were taken 21 days after initiation of the stress treatment. The relative humidity was maintained at $\sim 60 \%$. The experiments were repeated twice with three replicates in each experiment.

\section{Freezing tolerance test}

Three-week-old seedlings of wild type and transgenic plants grown on MS medium were cultured at $4{ }^{\circ} \mathrm{C}$ for one day under long day condition (16-h light/8-h dark). After cold acclimation, the plants were left at $-20^{\circ} \mathrm{C}$ for 1 or $2 \mathrm{~h}$, transferred immediately to $4^{\circ} \mathrm{C}$ for another $12 \mathrm{~h}$ (overnight). Subsequently, plants were kept in the greenhouse at $25^{\circ} \mathrm{C}$ and observed further. Photographs were taken seven days after initiation of the recovery growth in the greenhouse.

Determination of proline concentration

Four-week-old seedlings grown on MS medium were transferred onto filter paper in a Petri dish saturated with 100 - or $200-\mathrm{mM} \mathrm{NaCl}$, incubated at $25 \pm 2{ }^{\circ} \mathrm{C}$ for $24 \mathrm{~h}$ under continuous white light. After the treatment, proline content was determined as described previously (Bates and Waldren 1973).

\section{Western blot analysis}

Leaves from either Arabidopsis or tobacco plants were ground in liquid $\mathrm{N}_{2}$ and suspended in $1.5 \mathrm{ml}$ of $30 \mathrm{mM}$ potassium phosphate buffer ( $\mathrm{pH} 7.5$ ) containing $40-\mathrm{mM}$ $\mathrm{NaCl}$ and 3-mM dithiothreitol (Powell 1986). Homogenates were centrifuged for $5 \mathrm{~min}$ at $12,000 \times \mathrm{g}$. Supernatants were transferred to new tubes, and protein concentrations were determined as described previously (Bradford 1976). A 10- $\mu$ g sample of total protein was mixed with loading buffer, boiled for $3 \mathrm{~min}$, and sizefractionated through electrophoresis in a $12.5 \%$ SDS polyacrylamide gel. Separated proteins were transferred to a PVDF membrane (Millipore Corporation) according to the manufacturer's instructions. A polyclonal antibody against AtIpk $2 \beta$ protein purified from recombinant $E$. coli was raised in rabbits. Antiserum was purified by $\operatorname{IgG}$ affinity purification. The anti-AtIpk $2 \beta$ antiserum was used at a 1:5,000 dilution in TBST. Peroxidase-labeled affinity purified secondary antibody isolated from a pool of serum from goats immunized with purified rabbit IgG was used at a 1:1,000 dilution in TBST (KPL Corporation).

Stress gene expression analysis using reverse transcription PCR

Three-week-old tobacco seedlings grown on MS agar plates were treated with $300-\mathrm{mM} \mathrm{NaCl}$ for $5 \mathrm{~h}$. Total RNA was isolated with TRIZOL Reagent (Invitrogen) and used for reverse transcription (RT) to generate first-strand cDNA. RT was performed on $2-\mu \mathrm{g}$ total RNA per reaction using ReverTra Ace (TOYOBO). A portion of the resulting cDNA was then subjected to PCR amplification using gene specific primers (Table 1). Expression level of the Nicotiana tabacum ACTIN gene, which served as reference, was monitored with NtActin forward and reverse primers (Table 1). 
Statistical analysis

For statistical analyses, the Student's $t$-test was used to generate every $P$-value. The alpha level was 0.05 . The tests were one-tailed. The data were normalized and all samples were normally distributed with homogeneity of variance.

\section{Results}

Yeast complementation with AtIpk2 $\beta$

In $S$. cerevisiae, the $A R G 82 / I P K 2$ gene encodes an inositol polyphosphate kinase (Odom et al. 2000). The S. cerevisiae $\arg 82 / I p k 2(\arg 82 \Delta)$ mutant strain that lacks Ipk2 activity has slowed growth at $30^{\circ} \mathrm{C}$ and is unable to grow at $37^{\circ} \mathrm{C}$ (Odom et al. 2000). We and others have reported previously that AtIpk $2 \beta$ rescues its growth defects at $37^{\circ} \mathrm{C}$ (Stevenson-Paulik et al. 2002; Xia et al. 2003). This result led us to postulate that AtIpk $2 \beta$ may also be able to rescue its growth defects when other abiotic stresses were imposed. We observed that under adverse growth conditions such as high salt concentration or upon osmotic stress treatment, growth of the $\arg 82 \Delta$ mutant was severely impaired when compared to that of the wild type (Fig. 1a). To test whether AtIpk $2 \beta$ restores the growth defect of the mutant strain under these conditions, we transformed it with the Arabidopsis AtIpk $2 \beta$ cDNA. Expression of AtIpk $2 \beta$ almost completely restored growth of the $\arg 82 \Delta$ mutant under both kinds of stresses (Fig. 1a). It also restored growth at $37^{\circ} \mathrm{C}$ (Fig. 1a), as reported earlier (Stevenson-Paulik et al. 2002; Xia et al. 2003). We also performed experiments using liquid media and observed again, that AtIpk $2 \beta$ restores growth under conditions of abiotic stress (Fig. 1b).

AtIpk $2 \beta$ is abiotic stress regulated in Arabidopsis

We were interested to know whether different kinds of stresses such as salinity, cold and drought, or treatment with ABA would affect AtIpk $2 \beta$ transcript levels in Arabidopsis plants. To this end we performed quantitative realtime PCR (qRT-PCR). In ten-day-old seedlings grown on MS medium, AtIpk $2 \beta$ transcript level increased slightly upon exposure to cold or drought stress, but decreased in response to salt or ABA treatment (Fig. S1A in Supplementary Material). These results showed that AtIpk $2 \beta$ is a stress responsive gene potentially involved in different abiotic stress- and ABA-triggered signaling pathways in plants. We further tested AtIpk $2 \beta$ protein level by Western blot analysis. Fourteen-day-old Arabidopsis seedlings grown on MS medium were subjected to different stress treatments for $24 \mathrm{~h}$. In seedlings treated with $500-\mathrm{mM}$ mannitol, AtIpk $2 \beta$ protein level increased slightly, however no significant changes in protein level were detected in seedlings subjected to cold or $\mathrm{NaCl}$ stress (Fig. S1B in Supplementary Material).

Constitutive expression of AtIpk $2 \beta$ in transgenic tobacco

To test whether constitutive expression of AtIpk $2 \beta$ affects abiotic stress tolerance in plants, we introduced its open reading frame (Fig. 2a) into the genome of tobacco (Nicotiana tabacum cv. SR-1) by Agrobacterium tumefaciens-mediated transformation. Expression of AtIpk $2 \beta$ in the transgenic plant was controlled by the Cauliflower Mosaic Virus (CaMV) 35S promoter. Forty-six independent transgenic plants ( $T_{0}$ generation) were obtained; six lines were grown to produce seeds. Transgenic plants homozygous for the 35S:AtIpk2 $\beta$ transgene were obtained and three lines (S13, S14 and S15) were chosen for further experiments. Constitutive expression of AtIpk $2 \beta$ did not affect overall plant morphology although the transgenic plants grew slightly faster than wild type plants under normal growth condition. Western blot analyses were performed to test for the presence of AtIpk $2 \beta$ protein. A $33-\mathrm{kDa}$ band corresponding to AtIpk $2 \beta$ was identified in Arabidopsis plants; similarly, 33-kDa AtIpk $2 \beta$ protein was detected in the transgenic but not the wild type tobacco lines (Fig. 2b), indicating that it was successfully expressed in the genetically modified plants.

Expression of AtIpk $2 \beta$ increases salt tolerance of transgenic tobacco plants

We first studied the salt tolerance of AtIpk $2 \beta$ expressing plants during germination and early stages of seedling development. Seeds of wild type and the three homozygous transgenic lines S13, S14 and S15 were germinated on MS medium containing different concentrations of $\mathrm{NaCl}$. Germination rates of wild type and transgenic seeds were similar when cultured on normal MS medium (Fig. 3a). However, germination of wild type seeds was significantly impaired on MS medium supplemented with 100- or 200-mM NaCl, whereas germination of transgenic seeds was less strongly affected. After eight days on high salt MS medium $(100-\mathrm{mM} \mathrm{NaCl})$, only $\sim 28 \%$ of the wild type seeds, but more than $70 \%$ of the seeds obtained from AtIpk $2 \beta$ expressing plants germinated (Fig. 3b). When sown on MS medium supplemented with $200-\mathrm{mM} \mathrm{NaCl}$, only $\sim 7 \%$ of the wild type seeds, but $\sim 30 \%$ of the transgenic seeds germinated after 18 days (Fig. 3c). At low 
Fig. 1 Expression of AtIpk $2 \beta$ in $S$. cerevisiae arg $82 \Delta$. (a) AtIpk $2 \beta$ rescues growth defects of the yeast $\arg 82 \Delta$ mutant under high salt or mannitol stress, and at $37^{\circ} \mathrm{C}$. Ten-fold serial dilutions of the strain were plated and incubated at $30^{\circ} \mathrm{C}$ for $48 \mathrm{~h}$ on YPD medium supplemented with either 0.4 - or $0.8-\mathrm{M} \mathrm{NaCl}$, or with 0.4 - or 0.8 $\mathrm{M}$ mannitol. Plates incubated at $37^{\circ} \mathrm{C}$ contained YPD medium without extra $\mathrm{NaCl}$ or mannitol. WT, wild type; $\arg 82 \Delta, \arg 82 \Delta$ mutant; $\arg 82 \Delta+$ AtIpk $2 \beta$, $\arg 82 \Delta$ mutant harbouring plasmid pYX212-AtIpk2 $\beta$. (b) Liquid yeast cultures. Cells were grown for three days to saturation in YPD medium $\left(\mathrm{OD}_{600}=12.0\right)$. Five $\mu 1$ of cell culture were then used to inoculate $3 \mathrm{ml}$ of defined synthetic minimal medium supplemented with different concentrations of $\mathrm{NaCl}$ or mannitol. Cell density was determined at various time points as absorbance at $600 \mathrm{~nm}$. Cells were grown at $30^{\circ} \mathrm{C}$. WT, wild type; $\arg 82 \Delta, \arg 82 \Delta$ mutant; $\arg 82 \Delta+$ AtIpk2 2 , $\arg 82 \Delta$ mutant harbouring pYX212-AtIpk $2 \beta$; $\arg 82 \Delta+$ vector, $\arg 82 \Delta$ mutant harbouring pYX212
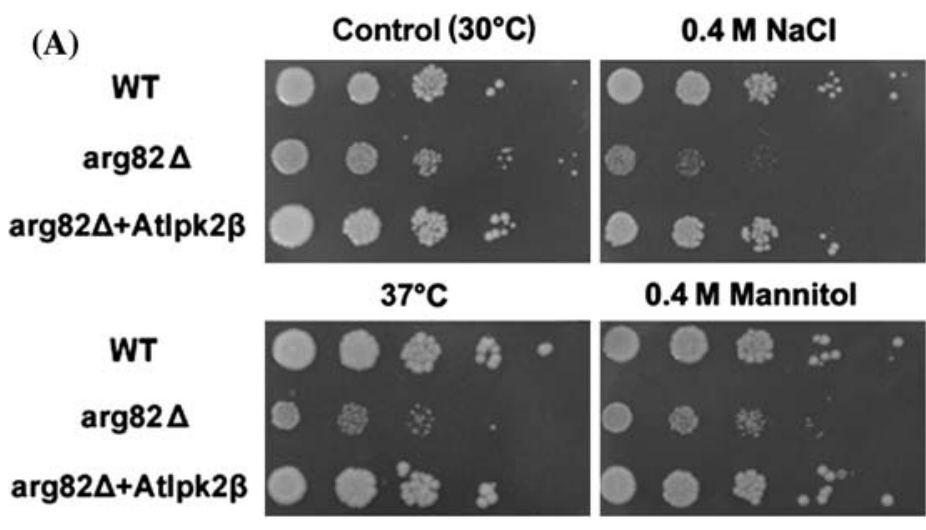

0.4 M Mannitol
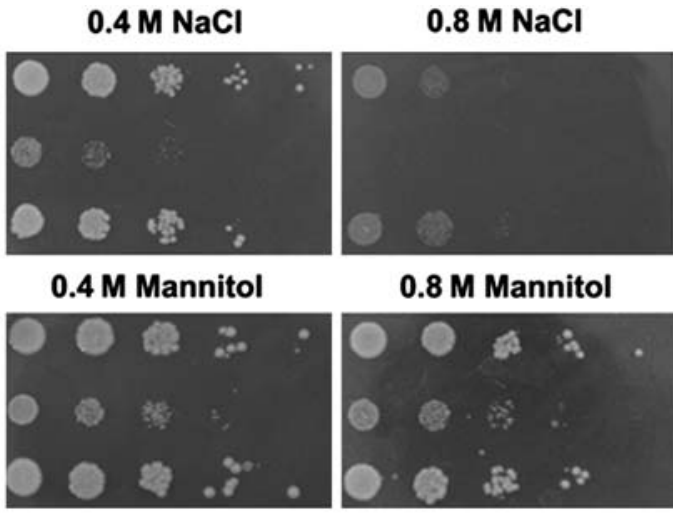

0.8 M Mannitol
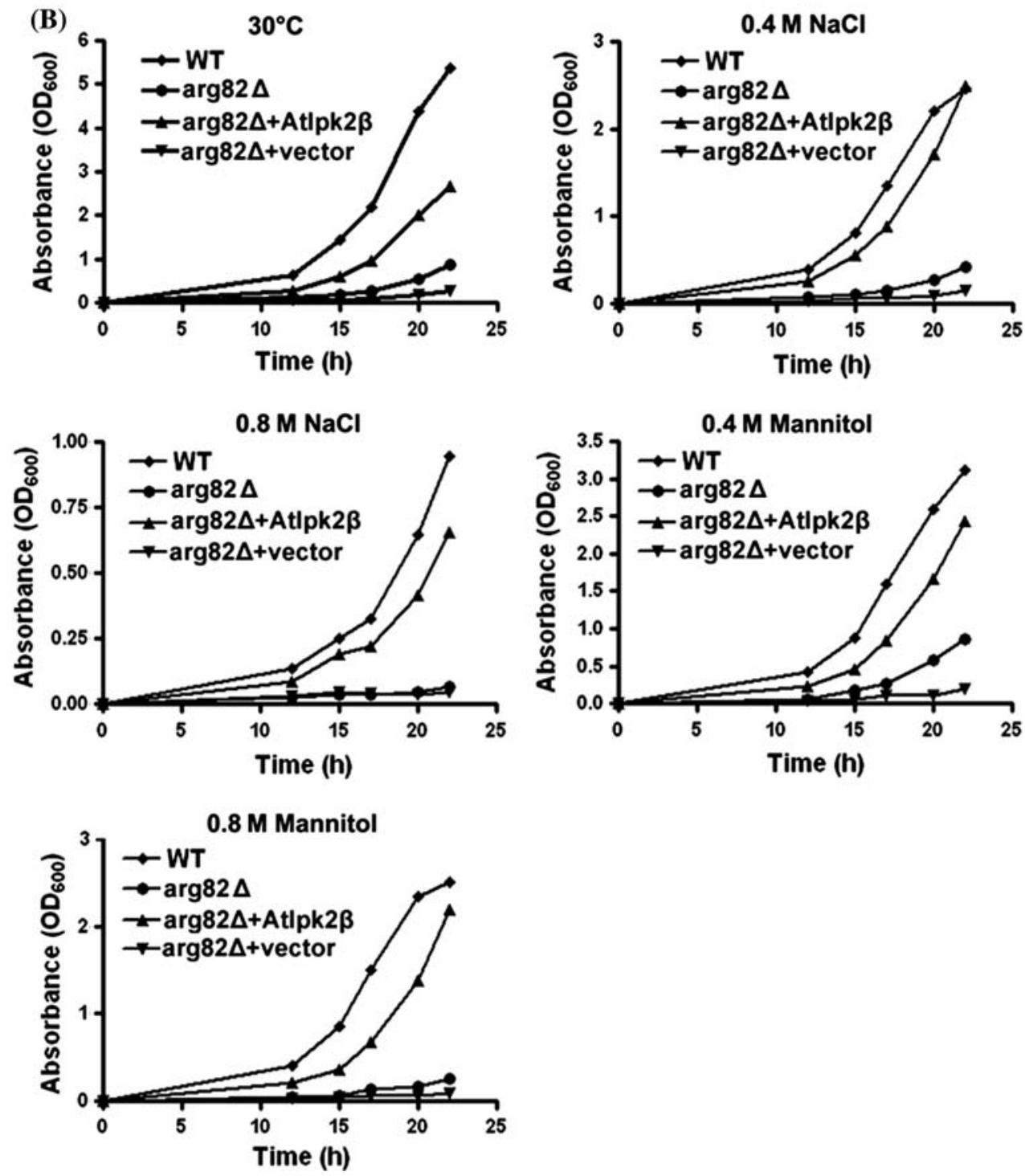
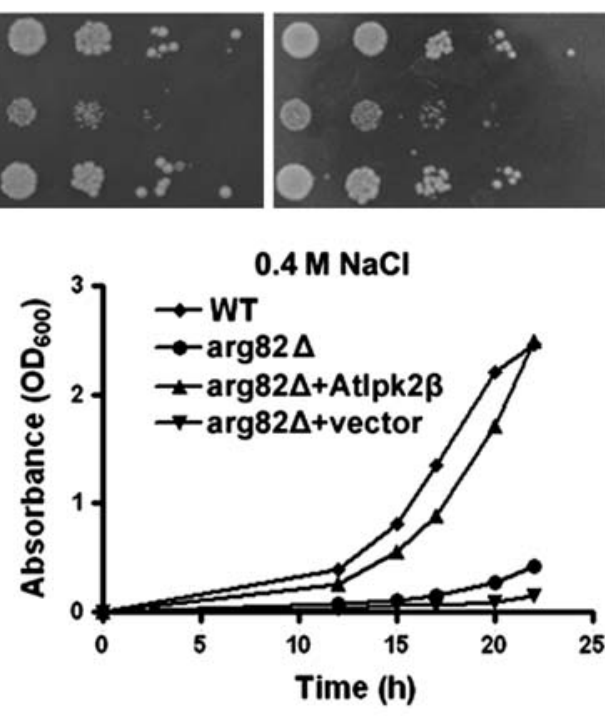

$0.4 \mathrm{M} \mathrm{NaCl}$ salt concentration $(50-\mathrm{mM} \mathrm{NaCl})$, wild type and transgenic seeds displayed similar germination rates (data now shown). At $150-\mathrm{mM} \mathrm{NaCl}$, both wild type and transgenic seeds germinated. However, development of wild type seedlings was impaired; plants produced smaller leaves and less root biomass than did transgenic seedlings (Fig. 3d). To further test the effect of salt on growth, 15-day-old wild type and transgenic seedlings were transferred to MS 


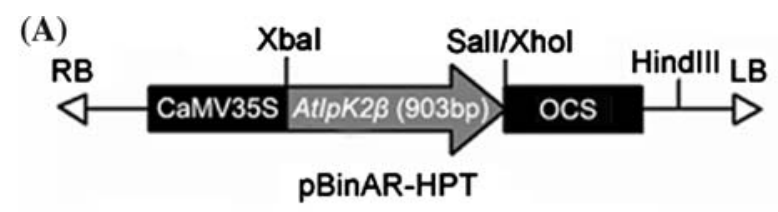

(B)

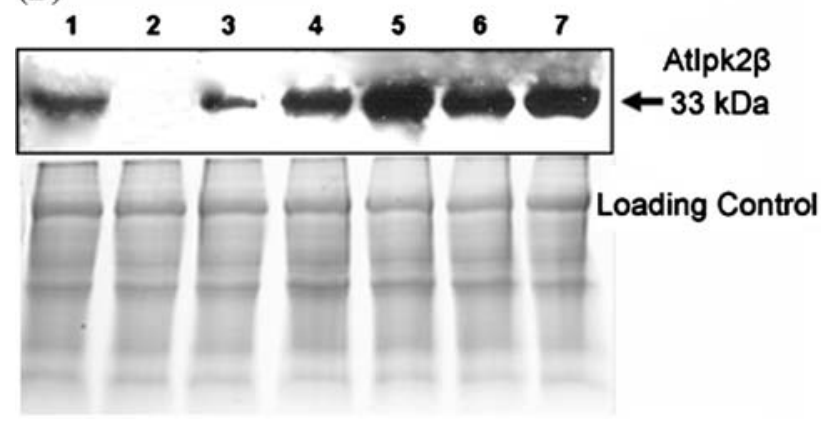

Fig. 2 Construct used for tobacco transformation and Western blot analysis of AtIpk $2 \beta$ in wild type and transgenic tobacco plants. (a) Schematic map of the binary construct used for tobacco transformation. Expression of AtIpk2 $\beta$ is driven by the Cauliflower Mosaic Virus 35S promoter. Ocs, ocs terminator; RB and LB, right and left border of T-DNA, respectively. (b) Western blot analysis. Lane 1, wild type Arabidopsis; lane 2, wild type tobacco; lanes 3-7, transgenic AtIpk $2 \beta$ expressing tobacco lines S11, S13, S14, S15, and S18. Coomassie Bright Blue stained gel is shown below the Western blot to demonstrate equal loading of protein

medium supplemented with $\mathrm{NaCl}$ at different concentrations. After two additional months, strong growth retardation was observed in wild type seedlings. Inhibition of growth was less evident in transgenic lines (Fig. 3e). A root-bending assay has previously been used to test the effect of elevated salt concentration on root growth (An et al. 2007; Zhu et al. 1998). At 50-mM $\mathrm{NaCl}$ on $\mathrm{MS}$ medium, root growth of both wild type and transgenic lines was accelerated, but it was inhibited at increasing $\mathrm{NaCl}$ concentrations. At 150-mM NaCl, inhibition of root growth was significantly more pronounced in wild type than in transgenic plants (Fig. 3f, g).

We also performed salt tolerance experiments with wild type and two transgenic lines grown in the greenhouse in soil. The plants were watered bi-weekly with $1 / 8$ concentrated MS salt solution supplemented with or without 200$\mathrm{mM} \mathrm{NaCl}$. After six weeks, distinct differences were observed between wild type and transgenic plants exposed to $200-\mathrm{mM} \mathrm{NaCl}$ (Fig. 4a). Although both sets of plants flowered under conditions of salt stress, wild type plants developed much shorter stems (Fig. 4b), produced fewer pods (Fig. 4c), and produced seeds that were not viable. We determined endogenous $\mathrm{Na}^{+}$levels in leaves and roots of wild type and transgenic plants grown in the absence or presence of 200-mM NaCl. Both wild type and transgenic plants exposed to salt contained elevated levels of $\mathrm{Na}^{+}$ions in leaves and roots (Fig. 4d), however, ion concentrations were not significantly different between wild type and transgenic plants (the same was true for plants grown under normal conditions). We also grew tobacco plants in hydroponic culture. In the absence of salt stress, no overt morphological difference was observed between wild type and transgenic plants. However, growth of wild type tobacco was severely inhibited in the presence of $300-\mathrm{mM}$ $\mathrm{NaCl}$ (Fig. 4e), leading to a depression of shoot height by about one third, and of plant fresh weight by about $50 \%$ in comparison to AtIpk $2 \beta$ expressing tobacco plants after a two-month stress treatment (Fig. 4f). All these results indicated that AtIpk $2 \beta$ alleviated the negative effects imposed by salt stress on plant growth.

Transgenic plants showed increased tolerance to osmotic, drought, freezing temperature and oxidative stress

In order to determine whether expression of AtIpk $2 \beta$ affects osmotic stress tolerance in plants, we watered wild type and transgenic tobacco plants (lines S13 and S15) with PEG-6000 (60 g/l) as described previously (Eltayeb et al. 2006). Under such experimental conditions, wild type plants were less vigorous, flowered earlier and produced smaller leaves than AtIpk2 $\beta$ expressing plants (Fig. 5a). We also tested the effect of water shortage on plant growth. After a 21-day drought period, wild type plants completely wilted, while transgenic plants were less severely affected (Fig. 5b). At the end of the drought tolerance test, the plants were re-watered and grown further to allow seed setting. Transgenic plants produced larger shoots than wild type plants (Fig. 5c).

Proline accumulation in response to osmotic or salinity stress has been well documented in prokaryotic and eukaryotic organisms (Schobert 1997). Here, we compared the proline content of wild type and transgenic plants treated with $100-$ or $200-\mathrm{mM} \mathrm{NaCl}$. Although proline accumulated in a dose-dependent manner in both wild type and transgenic plants, proline concentration was slightly higher in transgenic plants in the presence of $200-\mathrm{mM}$ $\mathrm{NaCl}$ (Fig. 5d).

The results presented in Fig. 4 show that AtIpk $2 \beta$ expression increased the salt tolerance of transgenic tobacco plants. Since salt stress exerts osmotic stress to plant cells in addition to its ionic toxicity, we further determined if AtIpk2 $\beta$ expression confers elevated tolerance to oxidative stress on transgenic plants. Leaf disks from wild type and transgenic tobacco plants were exposed to increasing concentrations of $\mathrm{H}_{2} \mathrm{O}_{2}$ for $72 \mathrm{~h}$. As shown in Fig. 6, transgenic plants exhibited a strong tolerance to oxidative stress. Leaf disks from wild type plants were almost completely bleached at the end of the stress 
Fig. 3 Germination rate and early seedling development of transgenic plants. $(\mathbf{a}-\mathbf{c})$

Percentage of germinating seeds of wild type (WT) and transgenic T2 plants (S13, S15) grown on MS medium supplemented with $0-, 100$ - or 200-mM NaCl. Results are presented as means and standard errors from three independent experiments $(\geq 100$ seeds of each line were sown for each experiment). (d) Wild type (WT) and transgenic seeds (S13, S15) geminated on MS medium supplemented with 50 or 150 $\mathrm{mM} \mathrm{NaCl}$. Photo was taken three weeks after seeds were sown. (e) Wild type (WT) and transgenic lines (S13, S14, S15) grown on MS medium supplemented with different concentrations of $\mathrm{NaCl}$ for 2 months. (f) Root bending assay of wild type (WT) and transgenic plants (S13, S15) on MS medium supplemented with 0 or $150-\mathrm{mM} \mathrm{NaCl}$.

Representative pictures are shown. (g) Primary root lengths of wild type (WT) and transgenic plants $(\mathrm{S} 13, \mathrm{~S} 15)$ in the presence of different salt concentrations. Root growth under control condition $(0-\mathrm{mM}$ $\mathrm{NaCl}$ ) was set to $100 \%$. The results are shown as means and standard errors from three independent experiments $(\geq 15$ seeds of each line were sown for each experiment). $* * *$ indicates significant differences in comparison to the wild type at $P<0.001$ (Student's $t$-test)
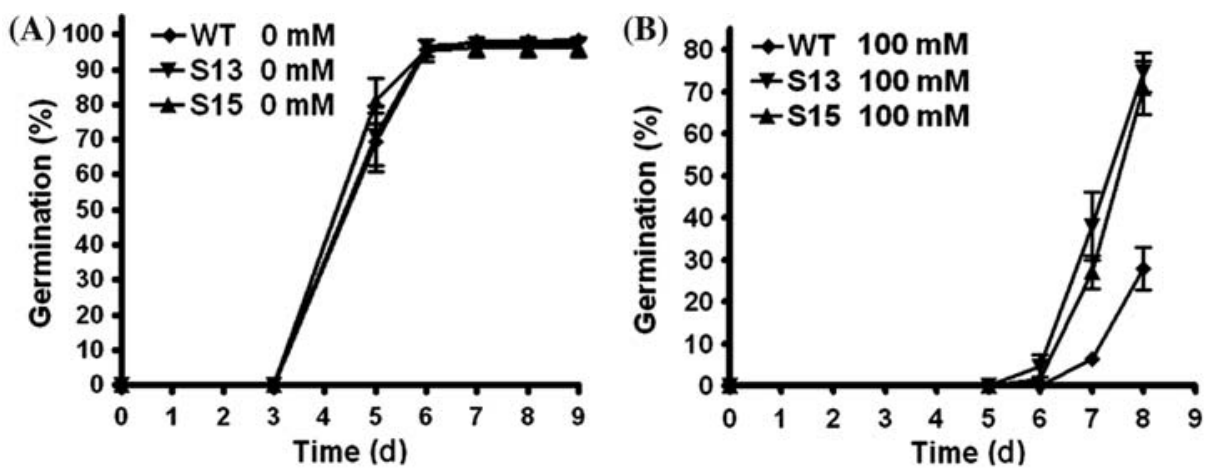

(E)
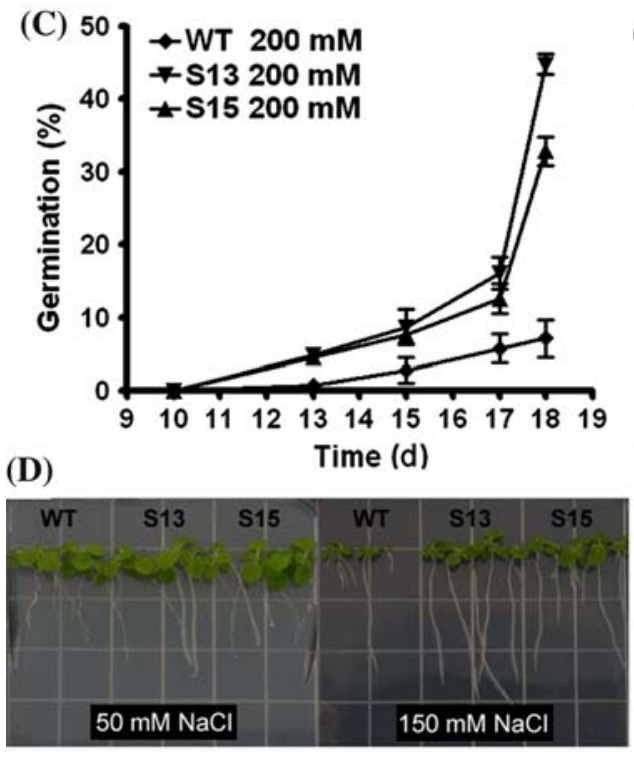

$0 \mathrm{mM} \mathrm{NaCl}$

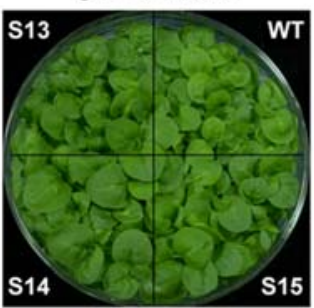

$200 \mathrm{mM} \mathrm{NaCl}$

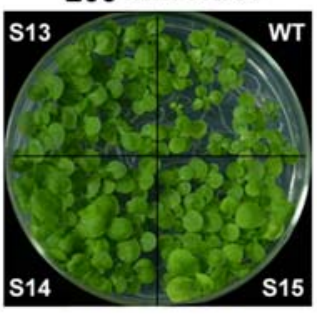

(G)

(F)

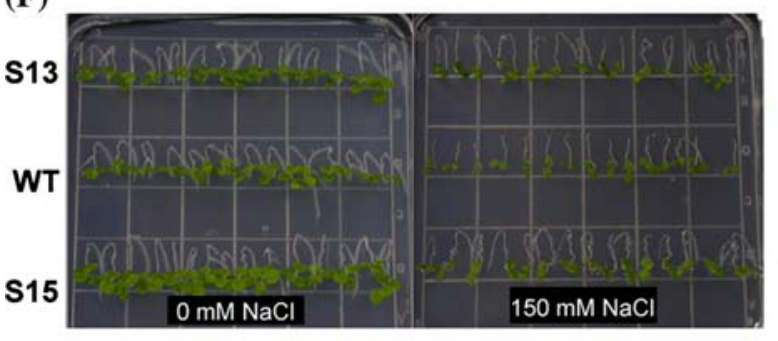

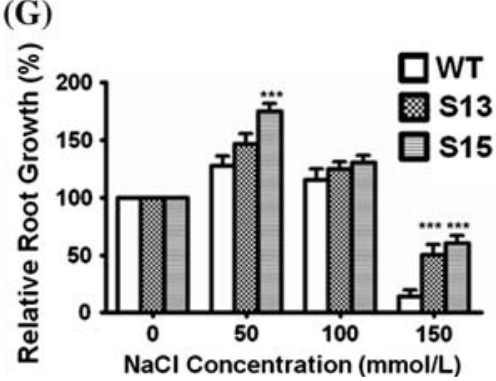

treatment, whereas those from transgenic plants showed significant resistance to $\mathrm{H}_{2} \mathrm{O}_{2}$-caused damage (Fig. 6a).

To further examine the effect of constitutive AtIpk $2 \beta$ expression on plant performance, the tolerance towards freezing temperature was analyzed. To this end, threeweek-old seedlings were kept at $-20^{\circ} \mathrm{C}$ for 1 or $2 \mathrm{~h}$, respectively, and subsequently allowed to recover for seven days in the greenhouse. Most transgenic plants resumed normal growth after the $2 \mathrm{~h}$ treatment at $-20^{\circ} \mathrm{C}$ (Fig. 6B), but only very few wild type plants did so. When treated for $1 \mathrm{~h}$ at $-20^{\circ} \mathrm{C}$, the damage was less severe, but again transgenic plants grew better than wild type plants after transfer back to the greenhouse (data not shown).
Transgenic seedlings showed a superior survival rate after short-term $-20^{\circ} \mathrm{C}$ treatment (Fig. 6c). In the presence of oxidative stress, chlorophyll loss was significantly delayed in AtIpk $2 \beta$ expressing plants compared to that of the wild type (Fig. 6d).

Lipid hydroperoxidation is an effective indicator of cellular oxidative damage (Yoshimura et al. 2004). Changes in the rates of lipid hydroperoxide production induced by oxidative stress were measured by determining MDA content in leaf disks. At high salinity (200-mM NaCl), MDA concentration markedly increased in wild type plants, whereas only a marginal increase was observed in the two transgenic lines (Fig. 7a). Although superoxide 
Fig. 4 Salt tolerance test to compare wild type and AtIpk $2 \beta$ expressing tobacco plants. For each experiment, twelve plants of each line were used. (a) Photograph of representative wild type (WT) and transgenic plants (S13, S15) watered with 200-mM NaCl for six weeks. (b), (c) Shoot height and pod numbers of wild type (WT) and transgenic (S13, S15) plants treated with $200-\mathrm{mM} \mathrm{NaCl}$.

* and ** indicate significant differences in comparison to the wild type at $P<0.05$ and $P<0.01$, respectively (Student's $t$-test). (d) $\mathrm{Na}^{+}$ content in leaves and roots of wild type (WT) and transgenic plants (S13, S15) grown in soil supplied with 0 or $200-\mathrm{mM}$ $\mathrm{NaCl}$ solution. (e) Photograph of a representative wild type (WT) and transgenic line S15 hydroponically grown in nutrient solution supplemented with $300-\mathrm{mM} \mathrm{NaCl}$ for two months. (f) Shoot height and (g) fresh weight of wild type (WT) and transgenic lines S13 and S15 grown for two months under control $(0-\mathrm{mM} \mathrm{NaCl})$ or high salt (300-mM NaCl) conditions. Results are presented as means and standard errors from three independent experiments. $* *$ indicates significant differences in comparison to the wild type at $P<0.01$ (Student's $t$-test)
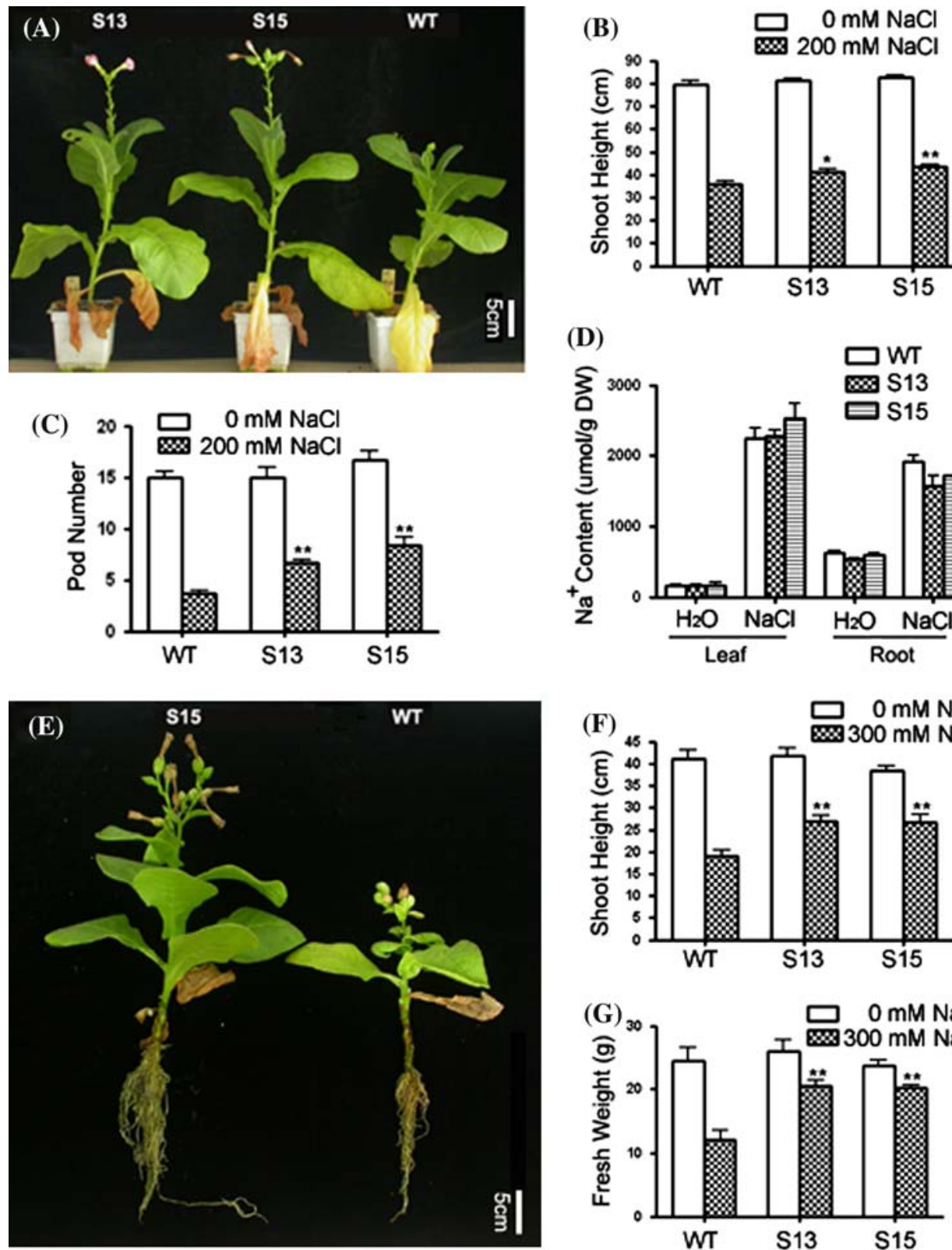
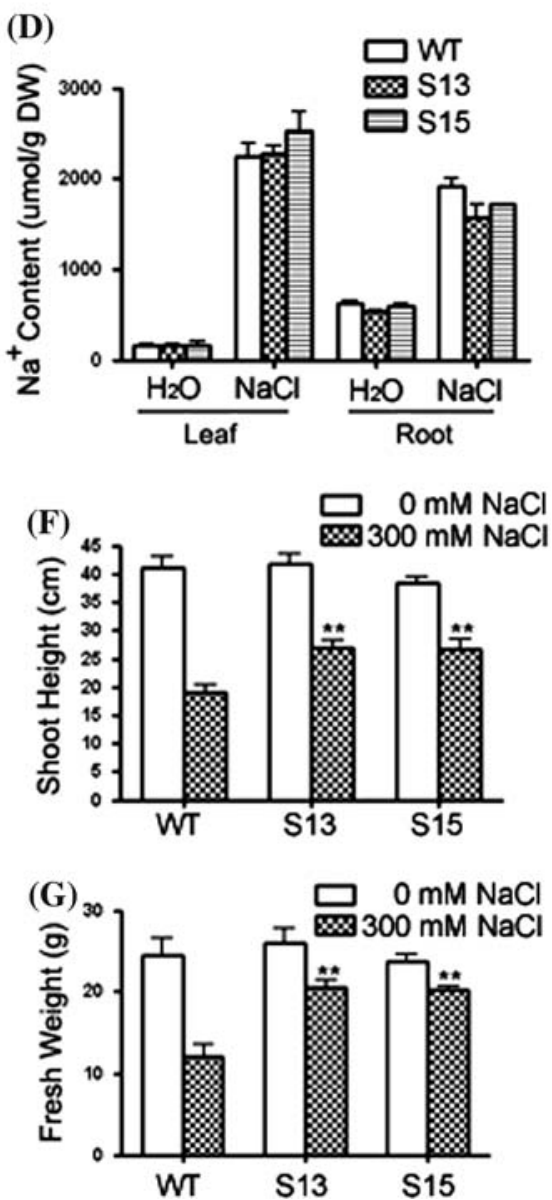

dismutase (SOD) activity was largely unaffected in wild type and transgenic plants treated with $1 \% \mathrm{H}_{2} \mathrm{O}_{2}$ (Fig. 7b), a slight elevation of APX activity was observed in transgenic plants (Fig. 7c). Also, catalase (CAT) activity increased in transgenic plants (Fig. 7d). These results indicate that constitutive expression of AtIpk $2 \beta$ enhanced tolerance to oxidative stress-induced membrane hydroperoxidation in transgenic tobacco plants.

Increased stress responsive gene expression in transgenic tobacco plants

Many genes responding to abiotic stress were cloned in recent years and used as molecular markers to monitor the activity of stress-signaling pathways in plants (Kasuga et al. 2004). The stress experiments described above suggested that AtIpk $2 \beta$ plays an important role in regulating stress tolerance in plants. To address whether or not AtIpk $2 \beta$ affects the expression of stress responsive genes, we investigated the transcriptional levels of five marker genes in wild type and transgenic tobacco plants by RT-PCR. The marker genes chosen are identical or homologous to those encoding lipid transfer protein, fructose-bisphosphate aldolase, raffinose synthase, chloroplast ATPase, and group 2 LEA proteins of tobacco. As shown in Fig. 7, transcript levels of these genes were higher in transgenic plants than in the wild type under both, normal and salt stress conditions (Fig. 7). 
Fig. 5 Effect of drought and osmotic stress on plant performance. For each experiment, twelve plants of wild type (WT) and each transgenic line (S13, S15) were used. (a) Wild type and transgenic plants grown in soil were watered with $60 \mathrm{~g} / \mathrm{l}$ PEG6000. Photograph was taken after 21 days of treatment. (b) Water was withheld for 21 days to impose drought stress. (c) Drought stressed plants were rewatered and grown for seed setting. (d) Proline content of wild type and transgenic plants after treatment with 100 or $200 \mathrm{mM} \mathrm{NaCl}$ for $24 \mathrm{~h}$. Results are presented as means and standard errors from three independent experiments. $* *$ indicates significant differences in comparison to the wild type at $P<0.01$ (Student's $t$-test)
(A) PEG $60 \mathrm{~g} / \mathrm{L}$

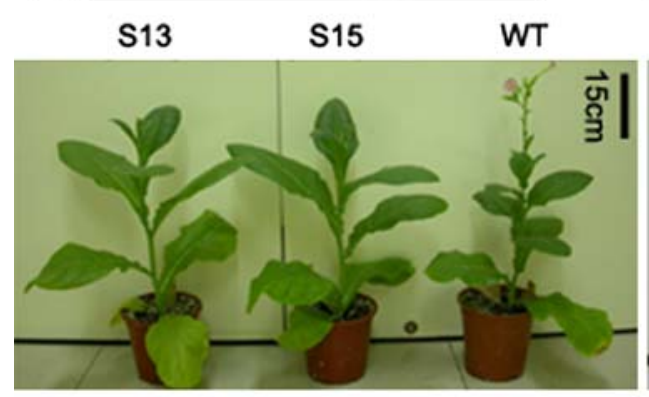

(C)

Rewater

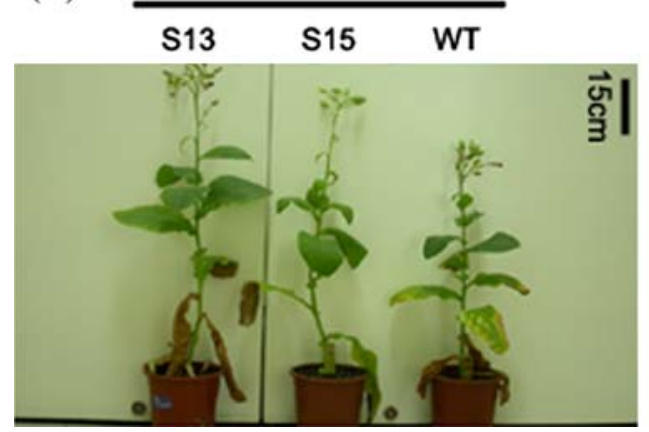

(B)

No Watering

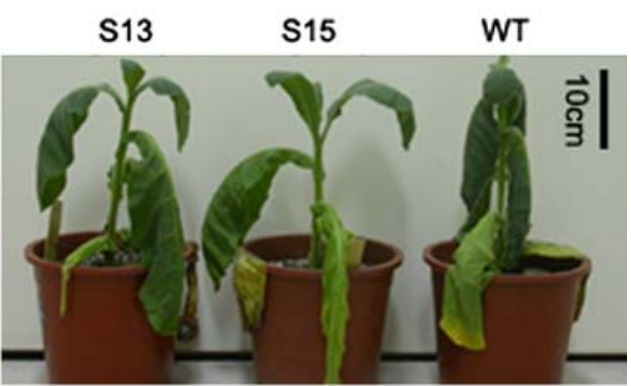

(D)

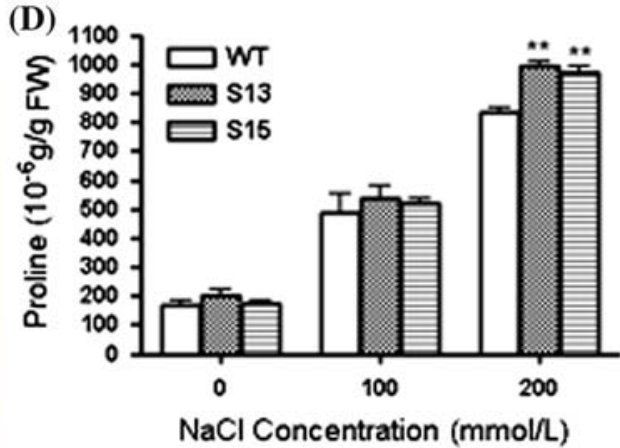

\section{Discussion}

A number of genes encoding $\operatorname{Ins}(1,4,5) \mathrm{P}_{3}$ 3-kinase or Ins $(1,4,5) \mathrm{P}_{3}$ dual specificity 6-/3-kinases were cloned and biochemically characterized in the past years. Examples include genes from yeast (Odom et al. 2000), animals (Bertsch et al. 1999), human (Dewaste et al. 2000), and higher plants (Stevenson-Paulik et al. 2002; Xia et al. 2003; Xu et al. 2005). It has recently been reported that in yeast ( $S$. cerevisiae) inositol polyphosphate kinase (Kcs1p) is required for resistance to salt stress, cell wall integrity, and vacuolar morphogenesis (Dubois et al. 2002), and that overexpression of D-IP3K1, a Drosophila $\mathrm{IP}_{3}$-kinase gene, confers resistance of flies to $\mathrm{H}_{2} \mathrm{O}_{2^{-}}$, but not to paraquat-induced oxidative stress (Monnier et al. 2002). Further genetic studies indicated that the protective effect conferred by elevated D-IP3K1 expression is mainly due to a lowered $\mathrm{IP}_{3}$ level and thus reduced $\mathrm{Ca}^{2+}$ ion release from internal stores, rather than an increased $\mathrm{IP}_{4}$ level.

Based on these observations, we were interested to know whether constitutive expression of AtIpk $2 \beta$ confers improved resistance to abiotic stresses on higher plants. Since the Arabidopsis AtIpk $2 \beta$ protein shares high amino acid sequence identity with the yeast IPK2 enzyme, which functions as a transcriptional regulator (also called $\operatorname{Arg} 82$ or ArgRIII) and displays dual-specificity $\mathrm{InsP}_{3}$-InsP $\mathrm{In}_{4}$ kinase activity (Odom et al. 2000), we first produced transgenic Arabidopsis (ecotype Columbia-0) plants overexpressing AtIpk $2 \beta$. Surprisingly, these plants did not exhibit a significant improvement to salt or osmotic stress in our preliminary studies (data not shown). This may be due to the possible overlapping/redundant functions of the two Arabidopsis inositol polyphosphate kinases (AtIpk $2 \alpha$ and AtIpk2 $\beta$ ) in vivo, as suggested earlier by the York group (Stevenson-Paulik et al. 2002). To examine this possibility, we further compared the growth of Arabidopsis wild type as well as transgenic AtIpk $2 \beta$ over-expresser (35S::AtIpk $2 \beta$ ) and knock-out mutant (atipk $2 \beta$, SALK 104995, ABRC) plants. All three types of plants had similar growth phenotypes when subjected to salt or osmotic stress (data not shown). Here we introduced AtIpk $2 \beta$ into tobacco plants and found that transgenic lines developed superior tolerance to various types of abiotic stresses.

Previously, AtNHXI, a vacuolar $\mathrm{Na}^{+} / \mathrm{H}^{+}$antiporter gene from Arabidopsis, was over-expressed in tomato and canola to improve the salt tolerance of transgenic plants (Zhang and Blumwald 2001). However, a comparative analysis of $\mathrm{Na}^{+}$and $\mathrm{K}^{+}$accumulation in leaves and roots of transgenic AtNHXI over-expressers and wild type plants grown under high-salt conditions was not performed because the high $(200 \mathrm{mM}) \mathrm{NaCl}$ concentration used in these experiments was lethal to the wild type plants. In the study reported here, the relatively high salt tolerance of wild type tobacco plants made it possible to perform such an analysis. In the presence of $200-\mathrm{mM} \mathrm{NaCl}$, despite a similar increase of $\mathrm{Na}^{+}$concentration in wild type and transgenic plants, slightly more $\mathrm{Na}^{+}$accumulated in leaves after long-term salt stress (Fig. 4d). This phenomenon is different from what has been seen in transgenic wheat 

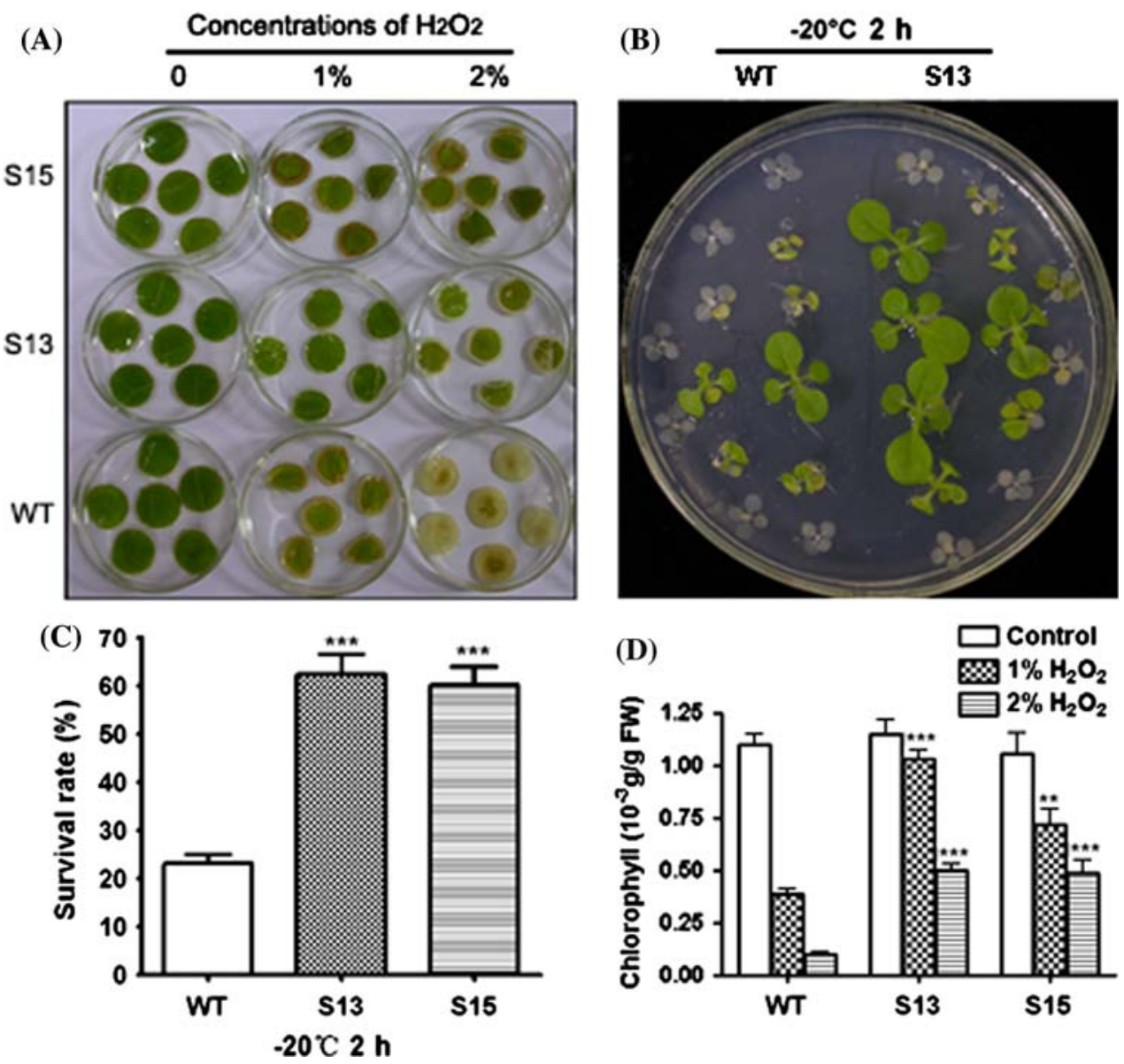

Fig. 6 Oxidative stress and short term freezing tolerance of wild type (WT) and transgenic tobacco plants (S13, S15). (a) Leaf disks were incubated in different concentration of $\mathrm{H}_{2} \mathrm{O}_{2}(1 \%$ and $2 \%$, respectively) under continuous white light for $72 \mathrm{~h} . \mathrm{H}_{2} \mathrm{O}_{2}$ induced leaf yellowing is delayed in the transgenic plants. (b) Three-week-old seedlings were stored at $-20^{\circ} \mathrm{C}$ for $2 \mathrm{~h}$, and then transferred to normal temperature for further growth. Photograph was taken seven days after the freezing treatment. (c) Quantification of the seedling survival rate (determined seven days after the freezing treatment). Results are presented as means and standard errors from three

overexpressing AtNHXI (Xue et al. 2004). Salinity causes two major damages to plant cells, water deficit resulting from the relatively high solute concentrations in the soil, and ion toxicity due to altered $\mathrm{K}^{+} / \mathrm{Na}^{+}$ratios as well as excessive $\mathrm{Na}^{+}$and $\mathrm{Cl}^{-}$contents (Apse and Blumwald 2002). The $\mathrm{Na}^{+} / \mathrm{H}^{+}$exchange activity of AtNHX1 is regulated in a $\mathrm{Ca}^{2+}$ - and $\mathrm{pH}$-dependent manner as reported earlier (Yamaguchi et al. 2005). The increased accumulation of salt in both leaves and roots suggests that unlike AtNHX1, which mainly works through sodium compartmentation, AtIpk $2 \beta$ may function through both sodium extrusion and compartmentation controlled by $\mathrm{Ca}^{2+}$ dependent signal transduction, although the precise mechanism of this still remains to be elucidated.

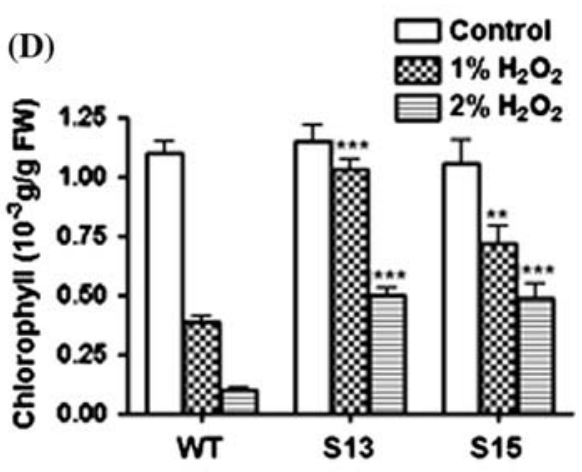

independent experiments. Fore each experiment, 40 seedlings of each line were used. $* * *$ indicates significant difference in comparison to the wild type at $P<0.001$ (Student's $t$-test). (d) Chlorophyll content was determined in leaf disks of wild type and $\mathrm{T}_{2}$ transgenic plants kept in $\mathrm{H}_{2} \mathrm{O}_{2}$ for $72 \mathrm{~h}$. Disks floated in water served as control. Results are preans and standard errors from three independent experiments. $* *$ and $* * *$ indicate significant differences in comparison to the wild type at $P<0.01$ and $P<0.001$, respectively (Student's $t$-test)

Proline contributes to osmotic adjustment (LeRudulier et al. 1989) and the protection of macromolecules during dehydration (Yancey et al. 1982), and as a hydroxyl radical scavenger (Hong et al. 2000). After treatment with 200$\mathrm{mM} \mathrm{NaCl}$, but not $100-\mathrm{mM} \mathrm{NaCl}$, proline accumulated to slightly higher levels in transgenic than in wild type tobacco plants (Fig. 5d). An increase in proline content was also observed in salt tolerant Arabidopsis with suppressed levels of proline degradation (Nanjo et al. 1999), transgenic salt tolerant tobacco plants with enhanced levels of proline biosynthesis (Kishor et al. 1995), and transgenic salt tolerant tomato plants overexpressing AtNHXI (Zhang and Blumwald 2001). So, it is possible that the elevated concentration of proline in transgenic plants helps to 
Fig. 7 MDA level, antioxidative enzyme activity, and expression level of stress regulated genes in transgenic plants. (a) MDA levels in wild type and transgenic lines S13, S15 after treatment with 200$\mathrm{mM} \mathrm{NaCl}$. (b-d) One-monthold seedlings were incubated for $12 \mathrm{~h}$ in $1 \% \mathrm{H}_{2} \mathrm{O}_{2}$ or water (control) under continuous white light. SOD, APX and CAT activities were determined. Results are presented as means and standard errors from three independent experiments. * and $* *$ indicate significant differences in comparison to the wild type at $P<0.05$ and $P<0.01$, respectively (Student's $t$-test). (e) Two-week-old seedlings of wild type and transgenic lines (S13, S15) were used for RNA extraction. For the salt stress experiments, seedlings were treated with $300-\mathrm{mM} \mathrm{NaCl}$ for $5 \mathrm{~h}$ before RNA isolation. The transcriptional levels of five stress genes were determined by RT-PCR analyses. The stress genes used for the tests are as follows: lipid transfer protein (AY562132); fructose-

bisphosphate aldolase (AY554169); raffinose synthase family protein/seed imbibition protein (AY554170); group 2 LEA proteins NtERD 10B (AB049336) and NtERD 10C (AB049337)
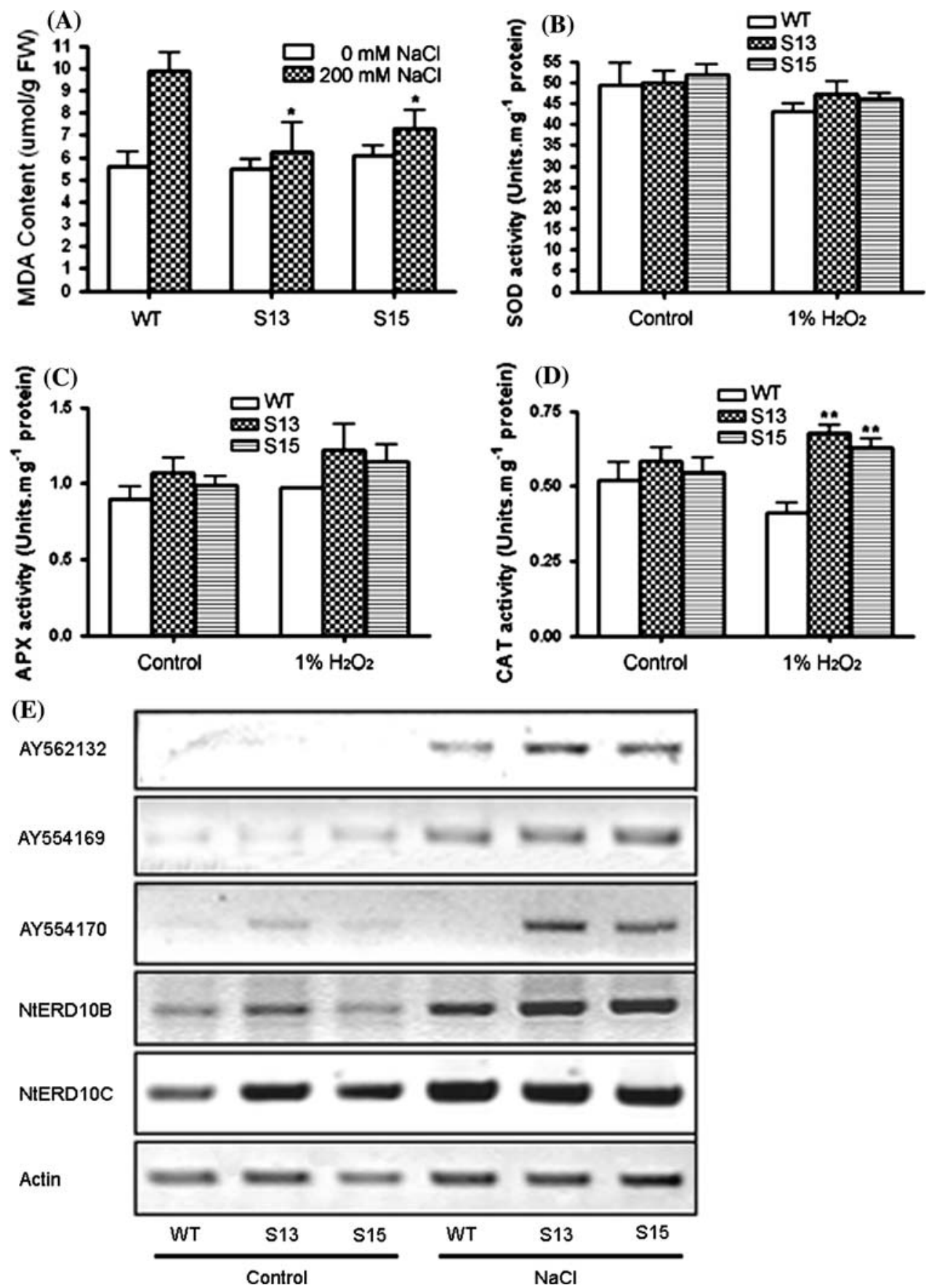

protect anti-oxidative enzyme thus alleviating the negative effects imposed by salt on transgenic AtIpk $2 \beta$ plants.

Salt-stress-induced generation of reactive oxygen species (ROS) has been thought as one of the major causes of adverse effects of high salinity. ROS are products of chloroplast and mitochondrial metabolism produced during stress; they cause membrane damage resulting in electrolyte leakage (Apse and Blumwald 2002). At 200-mM $\mathrm{NaCl}$, a relatively strong increase of MDA production was observed in wild type plants, but only a slight increase was seen in the two transgenic lines (Fig. 7a). Furthermore, catalase (CAT) activity increased significantly in transgenic plants after treatment with $1 \% \mathrm{H}_{2} \mathrm{O}_{2}$ (Fig. $7 d$ ). These results led us to hypothesize that constitutive expression of AtIpk $2 \beta$ improves cell membrane integrity. Evidence supporting this hypothesis was obtained from stress tolerance experiments with transgenic Arabidopsis overexpressing aldehyde dehydrogenase, or transgenic tobacco overexpressing Chlamydomonas glutathione peroxidase (Yoshimura et al. 2004).

The induction of stress-related genes has been taken as a hallmark of stress adaptation in plants (Thomashow 1999). 
Earlier studies have shown that lipid transfer proteins are induced by osmotic stress (Smart et al. 2000). Genes encoding plastidic aldolase are induced by salt (Yamada et al. 2000). Transgenic plants overexpressing such enzymes exhibit improved tolerance to the respective stresses. Here, we observed that constitutive expression of AtIpk $2 \beta$ under the control of the CaMV $35 \mathrm{~S}$ promoter triggered an increased expression of various stress responsive genes in transgenic tobacco. Already in the absence of salinity stress, transcript levels of genes encoding raffinose synthase family protein/seed imbibition protein (AY554170) and group 2 LEA protein NtERD 10C (AB049337) were found to be slightly elevated in the transgenic plants. At high salinity, the expression levels of genes encoding lipid transfer protein (AY562132) and raffinose synthase family protein/seed imbibition protein (AY554170) increased in the transgenic lines. These results suggest that AtIpk $2 \beta$ acts in one or more signal transduction pathway(s) thereby affecting the activity of stressrelated genes and stress tolerance.

Many stresses evoke an elevation of the cytosolic calcium ion concentration, including salinity (Knight et al. 1997), drought (Knight et al. 1997), cold (Knight et al. 1996), and oxidative stress (Sanders et al. 2002). Previously, it has been shown that salinity and osmotic stress induce a rapid and transient increase of $\mathrm{IP}_{3}$ levels (DeWald et al. 2001;Takahashi et al. 2001), and the reported accumulation of $\mathrm{IP}_{3}$ occurs during a time frame similar to that observed for stress induced $\mathrm{Ca}^{2+}$ mobilization. Therefore, the possibility exists that enhanced abiotic stress tolerance of transgenic AtIpk $2 \beta$ plants results from changes of $\mathrm{Ca}^{2+}$ dependent signaling. Whether this is indeed the case has to be analyzed in future studies

Plant growth and productivity are severely affected by abiotic stress. Augmented resistance towards various environmental stresses has been a desirable goal for genetic improvement of plants. Stress tolerance can for example be improved by altering the expression of stress-responsive genes in transgenic plants. Representatives include genes encoding chitinase and glucanase (Hong and Hwuang 2006), betaine aldehyde dehydrogenase (Yang et al. 2005), tonoplast and plasma membrane $\mathrm{Na}^{+} / \mathrm{H}^{+}$antiporters (Zhang and Blumwald 2001; Apse and Blumwald 2002), protein kinases (Xiong and Yang 2003), transcription factors (Waller et al. 2006), peroxidases (Yoshimura et al. 2004), DNA helicase (Sanan-Mishra et al. 2005), and DNA binding protein (polypeptide; Kalifa et al. 2004). Although the precise mode of action of AtIpk $2 \beta$ in plant responses to stress remains elusive, the results in this work provide direct evidence that alteration of AtIpk $2 \beta$ expression can significantly modify plant tolerance to various abiotic stresses, indicating a great potential of this gene for engineering stress tolerant crops.
Acknowledgements We thank Professor E. Blumwald for critical reading of the manuscript and professor $\mathrm{B}$. Sun for raising the antibody against AtIpk $2 \beta$ protein. This work was supported by the following grants: National Natural Science Foundation of China (Grant No.: NSFC 30571196; 30471411; 30570155; 30521004; 30370142); National Basic Research Program of China (Grant No.: 2006CB100100); the National Special Key Project on Functional Genomics and Biochips of China; the Deutscher Akademischer Austauschdienst (DAAD); the Program for New Century Excellent Talents in Universities (NCET-04-0680); the Program for Changjiang Scholars and Innovative Research Teams in Universities (IRTO437). Bernd Mueller-Roeber thanks the Fonds der Chemischen Industrie (No. 0164389) and the'Interdisciplinary Research Centre Advanced Protein Technologieś (IZ-APT) of the University of Potsdam for financial support.

Open Access This article is distributed under the terms of the Creative Commons Attribution Noncommercial License which permits any noncommercial use, distribution, and reproduction in any medium, provided the original author(s) and source are credited.

\section{References}

An R, Chen QJ, Chai MF et al (2007) AtNHX8, a member of the monovalent cation:proton antiporter-1 family in Arabidopsis thaliana, encodes a putative $\mathrm{Li}^{+} / \mathrm{H}^{+}$antiporter. Plant $\mathrm{J}$ 49: $718-728$

Apse MP, Blumwald E (2002) Engineering salt tolerance in plants. Curr Opin Biotechnol 13:146-150

Badawi GH, Kawano N, Yamauchi Y et al (2004) Over-expression of ascorbate peroxidase in tobacco chloroplasts enhances the tolerance to salt stress and water deficit. Physiol Plant 121: 231-238

Bates LS, Waldren RP (1973) Rapid determination of free proline for water stress studies. Plant Soil 39:205-207

Berridge MJ (1997) Elementary and global aspects of calcium signaling. J Physiol 499:291-306

Bertsch U, Haefs M, Deschermeier C et al (1999) A novel A-isoformlike inositol 1,4,5-trisphosphate 3-kinase from chicken erythrocytes exhibits alternative splicing and conservation of intron positions between vertebrates and invertebrates. Gene 228:61-71

Bradford MM (1976) A rapid and sensitive method for the quantitation of microgram quantities of protein utilizing the principle of protein-dye binding. Anal Biochem 72:248-252

Burnette RN, Gunesekera BM, Gillaspy GE (2003) An Arabidopsis inositol 5-phosphatase gain-of-function alters abscisic acid signaling. Plant Physiol 132:1011-1019

Carland FM, Nelson T (2004) Cotyledon Vascular Pattern2-mediated inositol $(1,4,5)$ triphosphate signal transduction is essential for closed venation patterns of Arabidopsis foliar organs. Plant Cell 16:1263-1275

Communi D, Vanweyenberg V, Erneux C (1995) Molecular study and regulation of D-myo-inositol 1,4,5-trisphosphate 3-kinase. Cell Signal 7:643-650

DeWald DB, Torabinejad J, Jones CA et al (2001) Rapid accumulation of phosphatidylinositol 4,5-bisphosphate and inositol 1,4,5-trisphosphate correlates with calcium mobilization in salt-stressed Arabidopsis. Plant Physiol 126:759-769

Dewaste V, Pouillon V, Shears S et al (2000) Cloning and expression of a cDNA encoding human inositol 1,4,5-triphosphate 3-kinase C. Biochem J 352:343-351

Dubois E, Scherens B, Vierendeels F et al (2002) In Saccharomyces cerevisiae, the inositol polyphosphate kinase activity of Kcs1p is 
required for resistance to salt stress, cell wall integrity, and vacuolar morphogenesis. J Biol Chem 277:23755-23763

Eltayeb AE, Kawano N, Badawi GH et al (2006) Overexpression of monodehydroascorbate reductase in transgenic tobacco confers enhanced tolerance to ozone, salt and polyethylene glycol stresses. Planta 225:1255-1264

Hill TD, Dean NM, Boyton AL (1988) Inositol 1,3,4,5-tetrakisphosphate induces $\mathrm{Ca}^{2+}$ sequestration in rat liver cells. Science 242:1176-1178

Hong JK, Hwang BK (2006) Promoter activation of pepper class II basic chitinase gene, CAChi2, and enhanced bacterial disease resistance and osmotic stress tolerance in the CAChi2-overexpressing Arabidopsis. Planta 223:433-448

Hong ZL, Lakkineni K, Zhang ZM et al (2000) Removal of feedback inhibition of DELTA1-pyrroline-5-carboxylate synthetase results in increased proline accumulation and protection of plants from osmotic stress. Plant Physiol 122:1129-1136

Kalifa Y, Perlson E, Gilad A et al (2004) Overexpression of the water and salt stress-regulated Asrl gene confers an increased salt tolerance. Plant Cell Environ 27:1459-1468

Kishor PBK, Hong Z, Miao GH et al (1995) Overexpression of [delta]-pyrroline-5-carboxylate synthetase increases proline production and confers osmotolerance in transgenic plants. Plant Physiol 108:1387-1394

Knight H, Trewavas AJ, Knight MR (1996) Cold calcium signaling in Arabidopsis involves two cellular pools and a change in calcium signature after acclimation. Plant Cell 8:489-503

Knight H, Trewavas AJ, Knight MR (1997) Calcium signaling in Arabidopsis thaliana responding to drought and salinity. Plant $\mathbf{J}$ 12:1067-1078

Kasuga M, Miura S, Shinozaki K et al (2004) A combination of the Arabidopsis DREB1A gene and stress-inducible $r d 29 A$ promoter improved drought- and low-temperature stress tolerance in tobacco by gene transfer. Plant Cell Physiol 54:346-350

LeRudulier D, Strom AR, Dandekar AM et al (1989) Molecular biology of osmoregulation. Science 224:1064-1068

Lichtenthaler HK (1987) Chlorophylls and carotenoids: pigments of photosynthetic biomembranes. Methods Enzymol 148: 350-382

Monnier V, Girardot F, Audin W et al (2002) Control of oxidative stress resistance by $\mathrm{IP}_{3}$ kinase in Drosophila melanogaster. Free Radic Bio Med 33:1250-1259

Nanjo T, Kobayashi M, Yoshiba Y et al (1999) Antisense suppression of proline degradation improves tolerance to freezing and salinity in Arabidopsis thaliana. FEBS Lett 461:205-210

Odom AR, Stahlberg A, Wente SR et al (2000) A role for nuclear inositol 1,4,5-trisphosphate kinase in transcriptional control. Science 287:2026-2029

Pattni K, Banting G (2004) Ins(1,4,5) $\mathrm{P}_{3}$ metabolism and the family of $\mathrm{IP}_{3}$ 3-kinases. Cell Signal 16:643-654

Perera IY, Love J, Heilmann I, Thompson WF, Boss WF (2002) Upregulation of phosphoinositide metabolism in tobacco cells constitutively expressing the human type I inositol polyphosphate 5-phosphatase. Plant Physiol 129:1795-1806

Powell-Abel P, Nelson RS, De B et al (1986) Delay of disease development in transgenic plants that express the tobacco mosaic virus coat protein gene. Science 232:738-743

Sanan-Mishra N, Pham XH, Sopory SK et al (2005) Pea DNA helicase 45 overexpression in tobacco confers high salinity tolerance without affecting yield. Proc Natl Acad Sci USA 102:509-514

Sanders D, Pelloux J, Brownlee C et al (2002) Calcium at the crossroads of signaling. Plant Cell 14:401-417

Schobert B (1997) Is there an osmotic regulatory mechanism in algae and higher plants? J Theor Biol 68:17-26
Shi HZ, Zhu JK (2002) Regulation of expression of the vacuolar $\mathrm{Na}^{+} /$ $\mathrm{H}^{+}$antiporter gene $A t N H X I$ by salt stress and abscisic acid. Plant Mol Biol 50:543-550

Smart LB, Cameron KD, Bennett AB (2000) Isolation of genes predominantly expressed in guard cells and epidermal cells of Nicotiana glauca. Plant Mol Biol 42:857-869

Stevenson-Paulik J, Odom AR, York JD (2002) Molecular and biochemical characterization of two plant inositol polyphosphate 6-/3-/5-kinases. J Biol Chem 277:42711-42718

Stevenson-Paulik J, Bastidas RJ, Chiou ST et al (2005) Generation of phytate-free seeds in Arabidopsis through disruption of inositol polyphosphate kinases. Proc Natl Acad Sci USA 102:1261212617

Takahashi S, Katagiri T, Hirayama T et al (2001) Hyperosmotic stress induces a rapid and transient increase in inositol 1,4,5-trisphosphate independent of abscisic acid in Arabidopsis cell culture. Plant Cell Physiol 42:214-222

Thomashow MF (1999) Plant cold acclimation: freezing tolerance genes and regulatory mechanisms. Annu Rev Plant Physiol Plant Mol Biol 50:571-599

Waller F, Muller A, Chung KM et al (2006) Expression of a WIPKactivated transcription factor results in increase of endogenous salicylic acid and pathogen resistance in tobacco plants. Plant Cell Physiol 47:1169-1174

Xia HJ, Brearley C, Elge S et al (2003) Arabidopsis inositol polyphosphate 6-/3-kinase is a nuclear protein that complements a yeast mutant lacking a functional ArgR-Mcm1 transcription complex. Plant Cell 15:449-463

Xiong L, Lee B-h, Ishitani M, Lee H, Zhang C, Zhu J-K (2001) FIERY1 encoding an inositol polyphosphate 1-phosphatase is a negative regulator of abscisic acid and stress signaling in Arabidopsis. Genes Dev 15:1971-1984

Xiong L, Schumaker KS, Zhu JK (2002) Cell signaling during cold, drought, and salt stress. Plant Cell 14(Suppl):S165-S183

Xiong L, Yang Y (2003) Disease resistance and abiotic stress tolerance in rice are inversely modulated by an abscisic acidinducible mitogen-activated protein kinase. Plant Cell 15: 745-759

Xu J, Brearley CA, Lin WH et al (2005) A role of Arabidopsis inositol polyphosphate kinase, AtIPK $2 \alpha$, in pollen germination and root growth. Plant Physiol 137:94-103

Xue ZY, Zhi DY, Xue GP et al (2004) Enhanced salt tolerance of transgenic wheat (Triticum aestivum L.) expressing a vacuolar $\mathrm{Na}^{+} / \mathrm{H}^{+}$antiporter gene with improved grain yields in saline soils in the field and a reduced level of leaf $\mathrm{Na}^{+}$. Plant Sci 167:849-859

Yamada S, Komori T, Hashimoto A et al (2000) Differential expression of plastidic aldolase genes in Nicotiana plants under salt stress. Plant Sci 154:61-69

Yamaguchi T, Aharon GS, Sottosanto JB, Blumwald E (2005) Vacuolar $\mathrm{Na}^{+} / \mathrm{H}^{+}$antiporter cation selectivity is regulated by calmodulin from within the vacuole in a $\mathrm{Ca}^{2+}$ - and $\mathrm{pH}$-dependent manner. Proc Natl Acad Sci USA 102:16107-16112

Yancey P, Clark M, Hand S et al (1982) Living with water stress: evolution of osmolyte systems. Science 217:1214-1222

Yang XH, Liang Z, Lu CM (2005) Genetic engineering of the biosynthesis of glycinebetaine enhances photosynthesis against high temperature stress in transgenic tobacco plants. Plant Physiol 138:2299-2309

Yoshimura K, Miyao K, Gaber A et al (2004) Enhancement of stress tolerance in transgenic tobacco plants overexpressing Chlamydomonas glutathione peroxidase in chloroplasts or cytosol. Plant J 37:21-33

Zhang HX, Blumwald E (2001) Transgenic salt-tolerant tomato plants accumulate salt in foliage but not in fruit. Nature Biotech 19:765-768 
Zhang ZB, Yang G, Arana F, Chen Z, Li Y, Xia HJ (2007) Arabidopsis inositol polyphosphate 6-/3-kinase (AtIpk2 $\beta$ ) is involved in axillary shoot branching via auxin signaling. Plant Physiol 144:942-951
Zhu JK, Liu JP, Xiong LM (1998) Genetic analysis of salt tolerance in Arabidopsis: evidence for a critical role of potassium nutrition. Plant Cell 10:1181-1191 